Observations de la planete (219) Thusnelda

faites a u reflecteur de $0^{\mathrm{m}} 50$ de l'observatoired'Alger.

\begin{tabular}{|c|c|c|c|c|c|c|c|c|c|}
\hline 1883 & T. M. Alger & $\Delta \alpha$ & $\Delta \delta$ & Comp. & $\alpha$ app. & $\log p .4$ & $\delta$ app. & $\log p \cdot \Delta$ & $*$ \\
\hline $\begin{array}{rr}\text { Mai } & 9 \\
10\end{array}$ & $\begin{array}{l}I^{\mathrm{h}} \mathrm{I}^{1} 4^{\mathrm{m}} \mathrm{I} 5^{\mathrm{s}} \\
\mathrm{IO} \quad 4 \mathrm{I} \quad 4 \mathrm{I}\end{array}$ & $\begin{array}{l}+0^{m} 17^{s} .25 \\
-138.52\end{array}$ & $\begin{array}{l}-\quad 0^{\prime} \text { I } 3.0 \\
+\quad 433.7\end{array}$ & $\begin{array}{l}\text { I } 5: 12 \\
\text { I } 2: 12\end{array}$ & $\begin{array}{l}16^{\mathrm{h}} 10^{\mathrm{m}} 3^{\mathrm{s}} \cdot 96 \\
16943.29\end{array}$ & $\begin{array}{l}9.319 u \\
9.4 I I_{n}\end{array}$ & 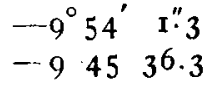 & $\begin{array}{l}0.800 \\
0.794\end{array}$ & I \\
\hline
\end{tabular}

Positions des étoiles de comparaison.

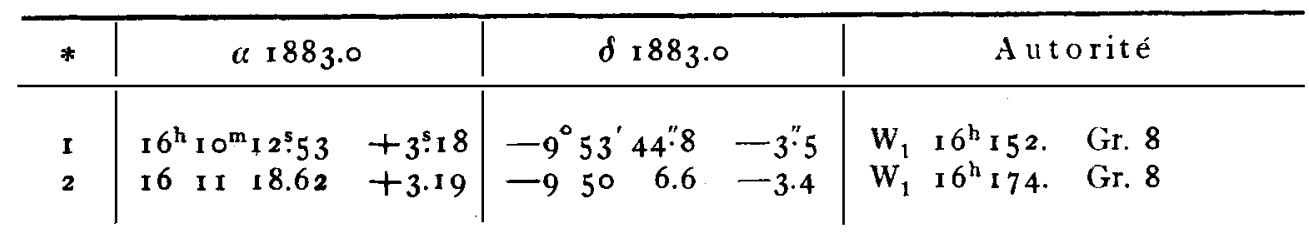

Alger 1883 Mai 12.

Ch. Trépied.

\title{
Observations of Comet 1882 III (Barnard)
}

made at the Cincinnati Observatory with r inch Equatoreal and Filar-Micrometer.

\begin{tabular}{|c|c|c|c|c|c|c|c|c|c|c|}
\hline 1882 & M. t. Mt L. & $\Delta a$ & & $\Delta \delta$ & Comp. & a app. & $\log p . \Delta$ & $\delta$ app. & $\log p \cdot \Delta$ & * \\
\hline Sept. 24 & $16^{\mathrm{h}} 32^{\mathrm{m}} 3^{\mathrm{s}}$ & $+0^{m} \quad 6: 88$ & $\longrightarrow$ & O'59:3 & I 4.6 & $7^{h} 40^{12} \times 9^{8} \cdot 4^{6}$ & $9.5 \circ 3$ & $+6^{\circ} 43^{\prime} 23^{\prime \prime} 5$ & 0.693 & $\mathbf{I}$ \\
\hline & I 6323 & to $29.5^{\circ}$ & & -- & 4.0 & $740 \quad 19.1$ & $9.5 \circ 3$ & - & 0.693 & 2 \\
\hline Oct. I I & I $5 \quad 3326$ & -0:2:58 & - & $\circ \quad \mathrm{I} .5$ & 8.4 & $\begin{array}{lll}8 & 29 & 2.15\end{array}$ & $9 \cdot 582$ & 一I $8 \quad 33 \quad 43.8$ & 0.818 & 3 \\
\hline » & 153326 & $-038.1 \mathrm{I}$ & - & $\circ 54.5$ & 8.4 & 829 & 9.582 & 一I $833 \quad 45.2$ & 0.8 I 8 & 4 \\
\hline$\gg$ & 153326 & $-0 \quad 58.60$ & + & 426.8 & 8.4 & $\begin{array}{lll}8 & 29 & 2.63\end{array}$ & $9 \cdot 5^{82}$ & $\begin{array}{lll}-18 & 33 & 48.9\end{array}$ & 0.8 I 8 & 5 \\
\hline 12 & 154347 & -235.68 & - & 422.1 & 6.4 & $83^{2} 54.90$ & 9.571 & $-20 \quad 25 \quad 77.6$ & $0.83^{\circ}$ & 6 \\
\hline 》 & $\begin{array}{lll}15 & 43 & 47\end{array}$ & $-2 \quad 4.83$ & & - & 6.0 & - & 9.571 & - & 0.830 & 7 \\
\hline I 3 & $\begin{array}{lll}15 & 28 & 13\end{array}$ & +251.67 & & 9177 & 8.4 & $\begin{array}{lll}8 & 3^{6} & 5^{2.62}\end{array}$ & 9.606 & $-22 \quad 25 \quad 12.1$ & 0.823 & 8 \\
\hline
\end{tabular}

Assumed mean places of comparison stars.

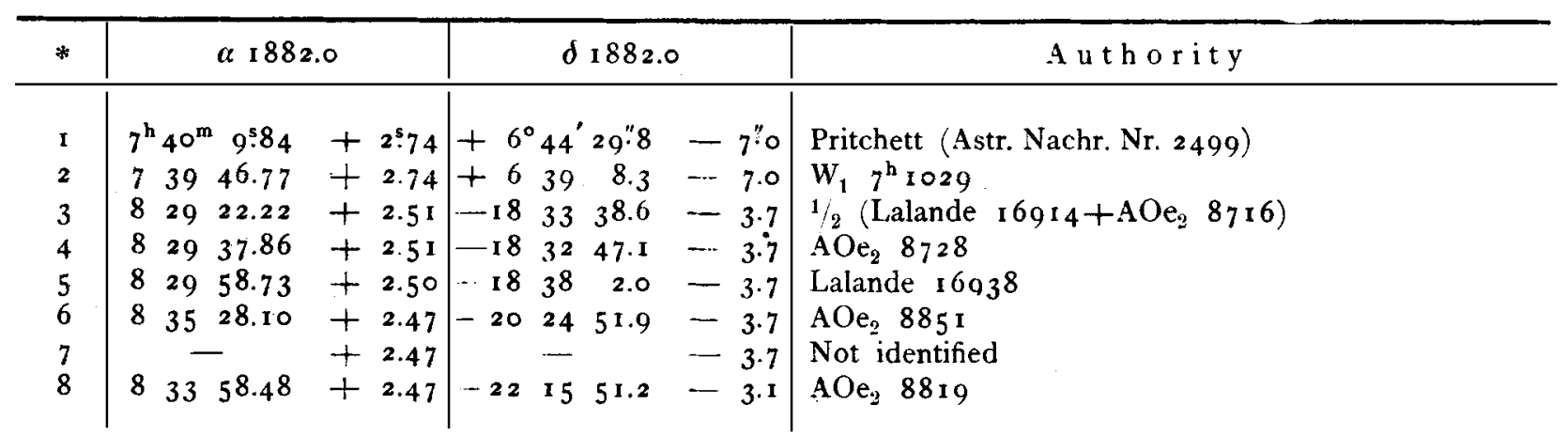

Sept. 24. Comet is very faint. No perceptible tail. 'There is a bright point in the center, very small, which was observed as the nucleus.

Oct. 1 I. Comet very faint in haze near the horizon. Slight central condensation.

Oct. 1 2. Comet strongly condensed in the center. No sign of a tail.

H. C. Wilson, Astronomer Pro. Tem. 